\title{
A comparison of softwood and birch kraft pulp fibers as raw materials for production of TEMPO-oxidized pulp, MFC and superabsorbent foam
}

\author{
Fredrik Wernersson Brodin • Hans Theliander
}

Received: 10 May 2013/Accepted: 24 August 2013/Published online: 3 September 2013

(C) The Author(s) 2013. This article is published with open access at Springerlink.com

\begin{abstract}
This study compares the suitability of using birch kraft pulp or softwood kraft pulp in the preparation of TEMPO-oxidized pulp, MFC and superabsorbent foam. TEMPO oxidation was performed using five different dosages of primary oxidant. The time of disintegration treatment was varied to study its influence on the properties of the produced MFCs and foams. Both the birch and the softwood pulps could be used for producing superabsorbent foams, depending on the process conditions, the absorption capacities were about the same for the two pulps and varied between 25 and $55 \mathrm{~g}$ saline solution/g absorbent. The foams based on birch pulp had, however, on average, $30 \%$ higher retention capacity than the foams based on softwood pulp. The maximum retention capacity obtained was $16.6 \mathrm{~g}$ saline solution/g absorbent. The greater retention capacity of birch-based foams is not fully understood, but a smaller pore size may be the reason, which in turn would generate greater capillary forces. In addition to this, it was found that birch pulps, contrary to softwood pulps, had a substantial amount of fibers that were relatively unaffected by the disintegration treatment. These oxidized fibers are likely to reinforce the foam, thereby making the foam more resistant to
\end{abstract}

F. W. Brodin $\cdot$ H. Theliander $(\square)$

Forest Products and Chemical Engineering, Department of Chemical and Biological Engineering, Chalmers University of Technology, 41296 Gothenburg, Sweden e-mail: hanst@chalmers.se external pressures, which is in accordance with earlier findings.

Keywords Absorbent · Foam - TEMPO · MFC · Kraft pulp $\cdot$ Birch

\section{Introduction}

In a disposable diaper, superabsorbent polymers (SAP) are used in combination with fluff pulp fibers to form the absorbent core of the diaper. Fluff pulp fibers provide integrity to the absorbent core and distribute liquid by means of capillary forces, while the main function of SAPs in the absorbent core is to absorb and retain large amounts of liquid (Nagorski 1994). More than $95 \%$ of super absorbents are synthetic SAPs, often based on cross-linked polyacrylic acids (Staples and Chatterjee 2002). Different concepts of superabsorbent foams are candidates for replacing multi-component absorbent cores (Allan 1998). Besides fulfilling the diverse functions of a multi-material absorbent core, the foams add benefits such as no dust being released to the air and no migration in the absorbent core. Several approaches have been proposed in the patent literature that build on two principal concepts. In the first concept, conventional SAP particles are incorporated in a non-superabsorbent foam, thus creating a composite structure (Harper et al. 1972; Kelly and Kim 1991; 
Griesbach 1996). The second concept builds on a homogeneous foam which utilizes capillary suction forces only, or in combination with osmotic pressure, to fulfill the absorbent function of the application (DesMarais et al. 1993; DesMarais et al. 1994; Jones et al. 1986).

An interesting option is to produce the absorbent materials from renewable materials such as MicroFibrillar Cellulose (MFC), which has been investigated in some earlier studies (Chatterjee and Makoui 1984; Makoui and Chatterjee 1987). These materials did, however, not reach the same good retention capacities of the commercial SAPs produced from polyacrylatic acid. In a recent study, a few MFC-based foams have been developed with a retention capacity of $12-15 \mathrm{~g} / \mathrm{g}$ in $0.9 \%$ saline solution, i.e. about half of the retention capacity of the commercial SAPs (Brodin and Theliander 2012), but the foams had a much quicker absorption rate. These foams were produced from bleached kraft pulp fibers in a process comprising TEMPO oxidation, separation of spent reaction liquid by pulp washing, disintegration of fibers into MFC and, finally, freeze drying the material to form an absorbent foam. This foam can also be combined with naturally stiff CTMP fibers thus forming a cellulosic composite material for application in absorbent articles such as disposable diapers (Brodin et al. 2012). The foam in the composite material reached about the same retention capacity as conventional SAPs. In Brodin and Theliander (2012), mainly softwood kraft pulp was used as the raw material in the preparation of this foam. However, a single foam sample prepared from birch kraft pulp showed improved liquid retention capacity in relation to the softwood sample prepared at the same conditions.

TEMPO oxidation has been utilized for selective and water-based oxidation of carbohydrates since the mid 1990s. This treatment adds new functionality to the substrate by oxidizing mainly primary hydroxyl groups to aldehyde and carboxylate groups (de Nooy et al. 1996). In addition to this, extensive depolymerization of the carbohydrate polymers has been reported due to $\beta$-elimination reactions in the alkaline reaction medium (Shibata and Isogai 2003). The $\mathrm{pH}$ and temperature dependence of TEMPO-oxidized pulp has been studied by Fujisawa et al. (2010), who found that depolymerization occurred at room temperature at $\mathrm{pH} 10-13$, while at the acidic condition, $\mathrm{pH}$ 1 , a temperature above $50{ }^{\circ} \mathrm{C}$ was necessary to achieve depolymerization. Furthermore, Saito et al. (2006) reported that TEMPO oxidation facilitates the fibrillation of pulp fibers into MFC, which initiated the usage of TEMPO oxidation as pretreatment in MFC preparation. Various TEMPO oxidation systems have been proposed (Bragd et al. 2000; Isogai et al. 2010; Jetten et al. 2000; Saito et al. 2009; Viikari et al. 1999), but the system used in this study was TEMPO/NaBr/ $\mathrm{NaClO}$ performed at weakly alkaline conditions, which is probably the most investigated TEMPOreaction system of today.

A few studies have previously been conducted on TEMPO oxidation using and comparing different raw materials. Isogai and Kato (1998) compared the solubility of various cellulose samples, including softwood and hardwood kraft pulps and found that neither of the substrates became soluble after a TEMPO oxidation at room temperature. Okita and Saito (2010) reported similar amounts of carboxylate for softwood and hardwood pulps after a dosage of $10 \mathrm{mmol} \mathrm{NaClO} / \mathrm{g}$ cellulose, i.e. $1.65 \mathrm{mmol} \mathrm{COO}^{-} / \mathrm{g}$ softwood pulp and $1.69 \mathrm{mmol} \mathrm{COO}^{-} / \mathrm{g}$ hardwood pulp. In another comparison, mild TEMPO oxidation resulted in $0.50 \mathrm{mmol} \mathrm{COO}^{-} / \mathrm{g}$ softwood pulp and $0.75 \mathrm{mmol} \mathrm{COO}^{-} / \mathrm{g}$ eucalyptus pulp (Syverud et al. 2011). Measurements of relative carbohydrate composition showed that the mannose and arabinose content in the softwood pulp decreased after mild oxidation treatment while neither of the pulps showed any significant change in xylose content. After a harsher TEMPO oxidation (10 $\mathrm{mmol} \mathrm{NaClO} / \mathrm{g}$ pulp), the total carbohydrate composition of the softwood and eucalyptus pulps composition was reported to be unknown due to a low hydrolysis yield (Rodionova et al. 2013). Measurements of transparency showed that a higher transparency was reached by using softwood pulp than eucalyptus pulp as the starting material (Rodionova et al. 2012; Rodionova et al. 2013). However, more research is needed to understand the phenomena that occur during the TEMPO oxidation of kraft pulps and the properties of the obtained oxidized pulps.

Various pre-treatment methods can be applied to reduce energy demand and improve the processablility of the mechanical disintegration, where dilute pulp suspensions are treated in an equipment such as homogenizer, microfluidizer or grinder to liberate microfibrils (Hubbe et al. 2008; Siro and Plackett 2010). Some studies have compared softwood and 
hardwood pulp fibers in the preparation of MFC. Stelte and Sanadi (2009) found that softwood pulp fibers were fibrillated to a greater extent than hardwood pulp fibers when subjected to the same refining treatment. The refined pulps were then subjected to homogenization where the birch pulp fibers needed more passes through the homogenizer than the softwood pulp to obtain MFCs with similar properties. Syverud et al. (2011) have reported lower fibrillation after homogenization when eucalyptus pulp fibers were used than if softwood pulp fibers were used, both without pretreatment and after a mild TEMPO oxidation. Nevertheless, neither of these studies has utilized the MFCs produced to prepare materials for absorbent purposes.

The aim of this study was to investigate the influence of raw material in the preparation of TEMPO-oxidized pulp, MFC and absorbent foam. Two fully-bleached chemical pulps were evaluated; a softwood kraft pulp and a birch kraft pulp. Furthermore, the dosage of primary oxidant and disintegration time were varied to enhance knowledge of the effects of TEMPO oxidation on wood derived based pulp fibers, and to investigate the effects on the MFC generated and absorption properties of the prepared absorbent foams.

\section{Experimental}

\section{Materials}

In this study two never-dried industrially produced totally chlorine-free bleached kraft pulps were used as the starting material; a Scandinavian softwood pulp (mixture of Picea abies and Pinus sylvestris) and a Scandinavian birch pulp (Betula pendula). Both bleaching sequences were based on oxygen, per-acetic acid and hydrogen peroxide.

\section{Methods}

The birch and softwood pulps were subjected to TEMPO oxidation according to the conditions given in Tables 1 and 2. All reactions and experiments were performed in a $2 \mathrm{~L}$ baffled glass vessel placed in a temperature-regulated water bath. The pulp slurry was stirred with a pitched-blade impeller $(\varnothing=4.4 \mathrm{~cm}$, $900 \mathrm{rpm})$. The reaction $\mathrm{pH}$ was measured and controlled with a $\mathrm{pH}$ stat (Titroline Alpha with a $50 \mathrm{~mL}$
Table 1 Amount of pulp subjected to TEMPO oxidation in the six dosages of $\mathrm{NaClO}$

\begin{tabular}{lllllll}
\hline & $\mathrm{a}$ & $\mathrm{b}$ & $\mathrm{c}$ & $\mathrm{d}$ & $\mathrm{e}$ & $\mathrm{f}$ \\
\hline $\mathrm{NaClO}(\mathrm{mmol} / \mathrm{g}$ & 0 & 1.25 & 2.5 & 3.75 & 5 & 6.25 \\
$\quad$ pulp) & & & & & & \\
Birch pulp (g) & - & 7 & 7 & 7 & 13 & 7 \\
Softwood pulp (g) & - & 7 & 7 & 7 & 13 & 7 \\
\hline
\end{tabular}

dosing unit) and the $\mathrm{pH}$ was kept constant at $\mathrm{pH}$ $10 \pm 0.2$ during the reaction by additions of $0.5 \mathrm{M}$ $\mathrm{NaOH}$. The reaction was continued until the need for the addition of $\mathrm{NaOH}$ ended. The oxidized pulp was washed and separated from the spent reaction liquid by filtration using a Büchner funnel with a nylon web (17 mesh per $\mathrm{cm}$ ) followed by washing with $2 \mathrm{~L}$ of deionized water.

The oxidized pulp fibers were disintegrated using an Ultra-Turrax T50 with an S50 N-G45F dispersing element. Pulp suspensions were prepared in batches of $1.5 \mathrm{~g}$ pulp, and to enable good mixing even in the most viscous suspensions a low pulp consistency $(0.6 \%)$ was chosen. A standard treatment time of 6 min was chosen for all ten oxidized pulps. In addition, a series of disintegration experiments were performed by subjecting one birch pulp (Be) and one softwood pulp (Se) to 1, 3, 6, 10 and 15 min disintegration time, using $1.5 \mathrm{~g}$ of pulp for each experiment.

The disintegrated pulp samples were freeze-dried to obtain porous absorbent materials. $20 \mathrm{~g}$ of wet sample was put in a Pyrex beaker $(\varnothing=47 \mathrm{~mm})$ and thereafter frozen by placing the beaker in liquid nitrogen $\left(-196{ }^{\circ} \mathrm{C}\right)$. Frozen samples were put in a Labconco Triad freeze dryer for $60 \mathrm{~h}(0.37$ mbar pressure, $-20{ }^{\circ} \mathrm{C}$ shelf temperature) to sublimate the water. Dried samples were stored in sealed plastic bags at ambient conditions.

\section{Analysis}

The pulp yield after TEMPO oxidation was determined gravimetrically. $1 \mathrm{~g}$ of wet pulp (including water) was dried in an oven at $105^{\circ} \mathrm{C}$ over night $(16 \mathrm{~h})$.

The amount of carboxylate groups was characterized based on the principle of sorption of methylene blue (Davidson 1948). A detailed description of the procedure is found in Brodin and Theliander (2012). In this study, a Specord 205 (analyticjena) UV/Vis- 
Table 2 Oxidation conditions

\begin{tabular}{lllll}
\hline Pulp consistency $(\%)$ & $\mathrm{pH}$ & Temperature $\left({ }^{\circ} \mathrm{C}\right)$ & TEMPO $(\mathrm{mmol} / \mathrm{L})$ & $\mathrm{NaBr}(\mathrm{mmol} / \mathrm{L})$ \\
\hline 1.0 & $10.0 \pm 0.2$ & 30 & 1 & 10 \\
\hline
\end{tabular}

spectrophotometer was used to determine the residual concentration of methylene blue (wavelength $664 \mathrm{~nm}$ ) in the solution after sorption experiments. The amount of carboxylate groups in the pulp was calculated based on the consumption of dye during sorption experiments and the dry weight of the pulps after subtracting the weight provided by the sorbed dye. The pooled standard deviation based on duplicate measurements was $0.054 \mathrm{mmol} / \mathrm{g}$ pulp.

The water retention value (WRV) of pulp samples was analyzed according to the standard method SCAN-C 62:00 but with the following changes: A sample size of $0.5 \mathrm{~g}$ of washed oxidized pulp was used per measurement, and deionized water was used to dilute the pulp sample to $10 \%$ pulp consistency before centrifugation. Duplicates of all samples were made. The pooled standard deviation was $0.08 \mathrm{~g} / \mathrm{g}$.

A test for intrinsic viscosity was performed according to the standard method SCAN 15:62. Samples of oxidized pulp were treated with $\mathrm{NaBH}_{4}$ to reduce the aldehyde groups in the pulp to hydroxyl groups (cf. Brodin and Theliander 2012) and thereby minimize further degradation of the dissolution of the carbohydrates in the analysis procedure. The reduced pulps were freeze-dried prior to intrinsic viscosity analysis. The viscosimetric average degree of polymerization $\left(\mathrm{DP}_{\mathrm{v}}\right)$ was calculated according to SCAN 15:62:

$\mathrm{DP}_{\mathrm{v}}=\sqrt[0.905]{0.75 \cdot[\eta]}$

Duplicates of all samples were made and the pooled standard deviation of the measurements was $8 \mathrm{DP}_{\mathrm{v}}$ units.

Pulp samples were prepared for carbohydrate analysis using reduction treatment (cf. Brodin and Theliander 2012), freeze drying and dry defibration in a hammer mill. The amount of mono sugars in the pulp samples (100 mg o.d. of pulp) was analyzed after acid hydrolysis (Theander and Westerlund 1986) using a Dionex ICS-5000 HPLC system, equipped with CarboPac PA1 columns and run with $\mathrm{NaOH}, \mathrm{NaOH} /$ $\mathrm{NaAc}(0.2 \mathrm{M})$ as eluents. An electrochemical detector was used for detection. The software used was Chromeleon 7, Chromatography data system, version 7.1.0.898. The sugar contents have been compensated for their specific reduction in hydrolysis yield according to Wigell et al. (2007). The content of cellulose, glucomannan and xylan in the pulps was calculated according the method described in the "Appendix".

Fiber and/or fibril size were analyzed using two instruments; a Kajaani FS300 fiber analyzer and a Malvern Mastersizer 2000. Fiber length, fiber width, fine content and fiber curl were measured with a Kajaani FS-300 (Metso), with results reported according to TAPPI T271. This test is most relevant for pulps with a high content of fibers in relation to microfibrils. However, if a sample has a high content of microfibrils instead a more complete size characterization can be obtained using laser diffraction technique. The Malvern Mastersizer 2000 has a detection range from 0.02 to $2000 \mu \mathrm{m}$. It should be noted, however, that the Malvern Mastersizer 2000 assumes spherical particles when calculating particle size. This implies that the particle size in the size distributions should be considered as relative, since both fibers and fibrils have high aspect ratios (length to width relation) and deviate considerably from spherical geometry. In preparing a sample it is important to break up agglomerates without causing further disintegration of the sample. A very dilute suspension, $\sim 0.01 \%$ pulp consistency, was prepared by dispersing the sample with a kitchen mixer with unsharpened blades for $10 \mathrm{~s}$.

Scanning electron microscopy (SEM) was used to study the freeze-dried materials. Samples were prepared by cutting the dried material with a sharp scalpel. Prior to analysis, the samples were coated with a thin layer (approx. $10 \mathrm{~nm}$ ) of gold (JEOL JFC$1100 \mathrm{E}$ ion sputter). The microscope used was a Zeiss EVO HD 15, operated in high-vacuum mode.

Free swelling capacity (FSC) and centrifuge retention capacity (CRC) were measured according to Edana 440.1-99 and Edana 441.1-99. FSC analysis involves soaking samples in a saline solution for specified intervals and measuring their liquid uptake (by weight) after 1, 5 and 30 min of absorption time. CRC is the amount of liquid retained in a material after centrifugation. The methods deviated from the standard in two ways: the bags were allowed to drip for 2 min before FSC weight measurements and the 
sample amount was $25 \%$ of a test pad (0.03-0.25 g). The results from these measurements are reported as mean values based on four samples.

\section{Results and discussion}

Chemical and physical properties of TEMPOoxidized pulps

The effects of TEMPO oxidation treatment at five dosage levels of primary oxidant of birch and softwood kraft pulps were investigated (Bb-Bf and $\mathrm{Sb}-\mathrm{Sf}$ ). These pulps were also compared with samples of nonoxidized birch pulp (Ba) and non-oxidized softwood pulp (Sa). Table 3 shows that the gravimetrical pulp yield, after oxidation, increased at a low dosage of primary oxidant due to the conversion of hydroxyl groups into carboxylate groups, which have counterions in the form of sodium ions. At high dosages, however, the gravimetrical pulp yield decreased below $100 \%$, which suggests that some carbohydrate polymers were dissolved in the latter parts of the reaction. Analysis of negatively charged groups, in oxidized pulps mostly carboxylate groups, showed that the amount of carboxylate groups increased at a higher dosage of primary oxidant. No significant differences were observed in either gravimetrical yield or carboxylate groups between the two pulp types at any dosage of $\mathrm{NaClO}$, except for carboxylate groups at the harshest oxidation, but the difference in this case was only slightly greater than the expected experimental error. The WRV increased with the extent of oxidation treatment, which indicates that fiber swelling increased as more carboxylate groups were introduced. Thus, the carboxylate groups generated an increase in osmotic pressure between the fiber wall and the surrounding liquid (Scallan and Tigerstrom 1992). The dissolution

Table 3 Gravimetrical yield, amount of carboxylate groups $\left(\mathrm{COO}^{-}\right)$, water retention value (WRV) and degree of polymerization (DP) of birch (B) and softwood (S) kraft pulps of carbohydrates that takes place at extensive oxidation may also result in more open fiber wall morphology and reduced cohesive forces in the fiber wall. The WRV of birch pulp samples was consistently greater than that of softwood pulp samples and the differences were in all cases large enough to be significant. The DP decreased gradually with a higher dosage of primary oxidant, probably through $\beta$-elimination reactions in the alkaline reaction liquid (Fujisawa et al. 2010).

Carbohydrate compositions before oxidation indicate that the birch pulp (Ba) contained about $10 \%$-units more hemicelluloses, than the softwood pulp (Sa), cf. Table 4. In birch pulp, xylan contributed to more than $90 \%$ of the total hemicelluloses, while the softwood pulp contained about equal amounts of glucomannan and xylan. The results of the oxidized pulps showed that none or only a small amount of hemicelluloses were removed at a low dosage of primary oxidant, which is in agreement with Syverud et al. (2011). Nevertheless, at high dosages of oxidant a substantial part of the hemicelluloses was removed from the pulp fibers during the TEMPO oxidation treatment. Consequently, the cellulose content increased as the dosage of primary oxidant was increased. It was also found that the birch pulp, even after the harshest oxidation (Bf), still consisted of $17 \%$ hemicelluloses (mostly xylan) as compared to the softwood pulp (SF) with only $7 \%$ hemicelluloses. Furthermore, the fraction of xylan removed by the harshest oxidation was similar for both pulps, i.e. about $40 \%$ of the xylan present in the nonoxidized pulps. It should also be noted that the hydrolysis yield decreased with the increase in dosage of primary oxidant, which will discussed below.

\section{Influence on hemicelluloses}

Carbohydrate analysis of the softwood pulps showed that glucomannan was removed to a greater extent

treated with no oxidation (a) or TEMPO oxidation with various dosages of $\mathrm{NaClO}$ (b-f)

\begin{tabular}{lllllllllllll}
\hline & $\mathrm{Ba}$ & $\mathrm{Bb}$ & $\mathrm{Bc}$ & $\mathrm{Bd}$ & $\mathrm{Be}$ & $\mathrm{Bf}$ & $\mathrm{Sa}$ & $\mathrm{Sb}$ & $\mathrm{Sc}$ & $\mathrm{Sd}$ & $\mathrm{Se}$ & $\mathrm{Sf}$ \\
\hline NaClO & 0 & 1.25 & 2.5 & 3.75 & 5 & 6.25 & 0 & 1.25 & 2.5 & 3.75 & 5 & 6.25 \\
Grav. Yield & - & 104 & 104 & 95 & 91 & 91 & - & 102 & 101 & 97 & 96 & 92 \\
COO- & 0.12 & 0.63 & 0.97 & 1.54 & 1.62 & 1.77 & 0.07 & 0.57 & 0.95 & 1.51 & 1.66 & 1.91 \\
WRV & 1.62 & 2.11 & 2.96 & 3.33 & 3.48 & 4.91 & 1.37 & 1.70 & 2.10 & 2.84 & 3.05 & 4.70 \\
DP & 1140 & 717 & 583 & 513 & 413 & 372 & 1050 & 626 & 558 & 449 & 370 & 289 \\
\hline
\end{tabular}


Table 4 Composition of carbohydrates in the birch and softwood kraft pulps, hydrolysis yield including detected carbohydrates, solid residue after acid hydrolysis

\begin{tabular}{|c|c|c|c|c|c|c|c|c|c|c|c|c|}
\hline & $\mathrm{Ba}$ & $\mathrm{Bb}$ & $\mathrm{Bc}$ & $\mathrm{Bd}$ & $\mathrm{Be}$ & $\mathrm{Bf}$ & $\mathrm{Sa}$ & $\mathrm{Sb}$ & $\mathrm{Sc}$ & $\mathrm{Sd}$ & $\mathrm{Se}$ & $\mathrm{Sf}$ \\
\hline $\mathrm{NaClO}$ & 0 & 1.25 & 2.5 & 3.75 & 5 & 6.25 & 0 & 1.25 & 2.5 & 3.75 & 5 & 6.25 \\
\hline Cellulose & 73.8 & 73.1 & 73.6 & 77.1 & 80.3 & 82.4 & 83.7 & 86.4 & 88.7 & 90.1 & 91.3 & 93.0 \\
\hline Glucomannan & 2.0 & 1.9 & 1.8 & 1.9 & 1.8 & 2.3 & 9.2 & 6.8 & 4.6 & 3.7 & 3.4 & 2.8 \\
\hline Xylan & 24.2 & 25.0 & 24.5 & 20.9 & 17.9 & 15.2 & 7.1 & 6.8 & 6.8 & 6.2 & 5.4 & 4.1 \\
\hline Hydrolysis yield (\%) & 78.0 & 83.5 & 61.5 & 55.4 & 57.0 & 52.5 & 84.2 & 77.1 & 70.3 & 60.1 & 58.1 & 54.2 \\
\hline
\end{tabular}

than xylan during the oxidation treatment. This difference may be related to the chemical structure of the sugar monomers present in softwood glucomannan polymer, i.e. a backbone of mannose and glucose sugars and with galactose as substituents. All these contain primary hydroxyl groups, which are accessible to selective oxidation by TEMPO. The results suggest that even at mild oxidations much of the glucomannan was dissolved or removed from the pulp fibers, probably through oxidation and degradation reactions. The same trend was not observed in the birch pulp but for birch the initial content of glucomannan was much lower.

Xylans have a backbone consisting of xylose sugar monomers which have two secondary hydroxyl groups, but no primary hydroxyl groups. Thus, it is not likely that xylan will be oxidized to any significant degree by TEMPO oxidation, which was confirmed by Bowman et al. (2011) for birch xylan. Nevertheless, the xylan polymers retained in the pulp after the kraft process are slightly substituted by negatively charged groups e.g. 4-O-methylglucuronic acids and hexenuronic acids. The removal of xylan during TEMPO oxidation may be attributed to electrostatic repulsions between the slightly negatively charged xylan polymers and the negative charges introduced on cellulose and glucomannan polymers. Xylan may also be simultaneously released from the fiber wall if it is attached to a polymer which is dissolved. Diffusion of xylan from the fiber wall can also be facilitated by the increased openness of the fiber wall, due to swelling and the gradual losses of solid material. This may explain why xylan, only to minor extent, was repelled or removed at mild oxidations, while at harsher oxidations xylan was repelled or removed more rapidly.

\section{Influence on pulp yield}

In Fig. 1, the yield loss is plotted together with the calculated loss of hemicelluloses. The yield loss was calculated as the difference between the gravimetrical yield and the maximum yield, i.e. including the gain in yield contributed by the carboxylate groups and counter-ions. If the yield gain is included, the material loss is about $15 \%$ at the most extensive oxidation. The decrease in hemicellulose content shows that the hemicelluloses were the main reason for the decrease in yield at harsher oxidations. This means that a significant amount of hemicelluloses will be found in the spent reaction liquid after harsh oxidations.

\section{Influence on acidic hydrolysis yield}

The carbohydrate analysis also showed that the hydrolysis yield decreased at an increase in the dosage of primary oxidant, which may be explained by oxidized sugars not being detected in the sugar analysis and the higher resistance to hydrolysis of sugar units that contain carboxylate groups. This increased stability against acidic hydrolysis has been reported to be due to a, so called, inductive effect that both increases and decreases the probability of the hydrolysis of glucosidic bonds depending on the location of the carboxylic group in relation to the glucosidic bond (Marchessault and Ranby 1959). It has also been reported that this stabilizing effect prevents the hydrolysis of oxidized parts of hemicelluloses (Bowman et al. 2011; Sierakowski et al. 2000). In Fig. 2 it is found that the weight percentage of oxidized sugar monomers corresponds well with the loss in hydrolysis yield, especially at high dosages of primary oxidant. Thus, the solid residue collected after acid hydrolysis could be agglomerates of non- 


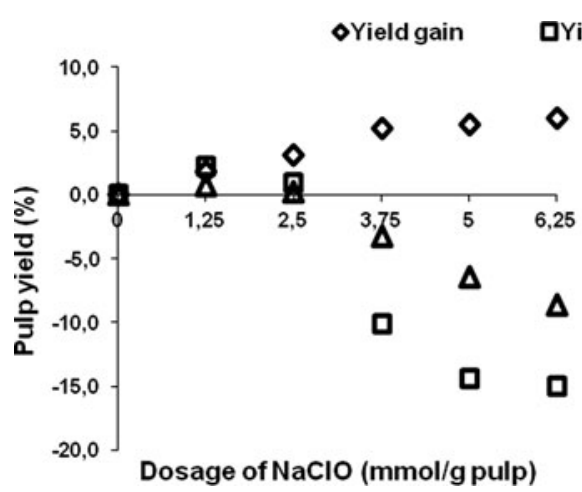

Fig. 1 Changes in pulp yield as an effect of oxidation treatment of birch (left) and softwood (right) kraft pulp. Yield gain is increase in yield due to oxidation of hydroxyl groups to carboxylate groups with a sodium counter-ion. Yield loss is the

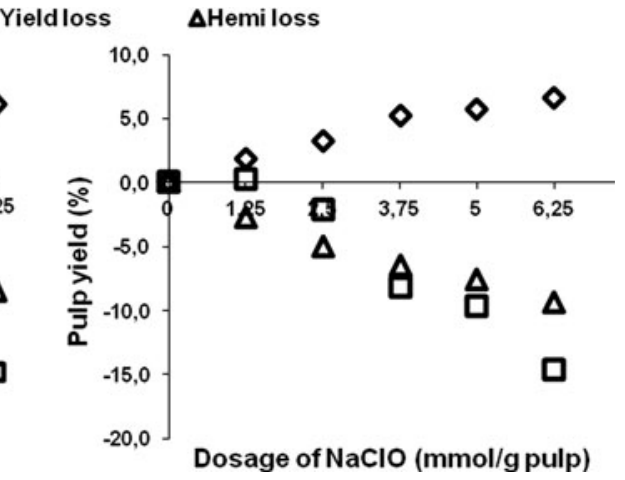

difference between max yield $(100 \%+$ yield gain $)$ and gravimetrical yield. Hemi loss is the reduction in pulp yield caused by decreased content of glucomannan and xylan in the pulp calculated from the relative carbohydrate composition
Fig. 2 Birch (left) and softwood (right) pulp weight fractions of undetected material after hydrolysis, weight fractions of sugars with a carboxylate group and weight fractions of solid residue collected after acid hydrolysis are plotted versus dosage of primary oxidant. Left figure shows birch samples and right figure shows softwood samples
口Hydrolysis yield loss

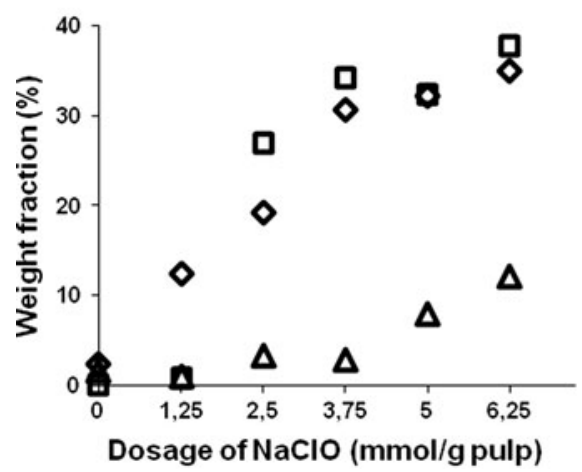

๑sugar acids $\Delta$ Solid residue

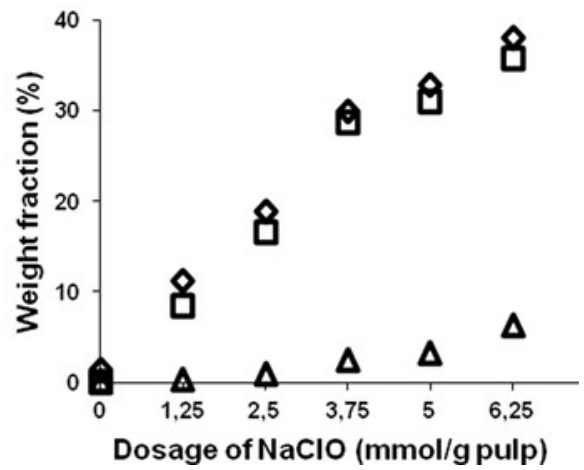

hydrolyzed polymers with carboxylate groups. It was also found that the birch pulp at high dosages of primary oxidant had more solid residue than the softwood pulp.

\section{Fiber and MFC characterization}

The pulps were characterized by fiber analysis and particle size, both before and after disintegration, to study the influence of oxidation and disintegration on fiber properties and particle size. It can be seen in Table 5 that oxidation treatment did not change fiber length, fiber width or the content of fines noticeably. However, due to the oxidation treatment there was a major decrease in fiber curl, i.e. the oxidized fibers were straighter than the original kraft pulp fibers. The greater swelling of the oxidized fibers together with more repellant forces between the carbohydrate polymers may explain this effect. This is in agreement with
Seth (2006), who showed that increased fiber swelling due to beating in a PFI-mill or carboxymethylation resulted in fiber straightening. The tendency towards increased fiber length is most likely an effect of the partial loss of fines during the washing operation and not a true increase in the length of the fibers. Analyses of the fiber length and the content of fines of the disintegrated samples showed that the samples treated with harsher oxidations were easier to disintegrate than samples treated with milder oxidation, in accordance with e.g. Saito et al. (2006) and Brodin and Theliander (2012). Particle size measurements confirmed that the disintegration of oxidized softwood pulp fibers was more rapid at high dosages of oxidant than for oxidized birch pulp fibers.

Figure 3 shows the particle size distributions of oxidized and disintegrated samples of birch and softwood pulps after 6 min of disintegration treatment. It can be seen that birch had a bi-modal shape at 
Table 5 Fiber analysis (Length $=\mathrm{L}$, Width $=\mathrm{W}$, Fines $=\mathrm{F}$ and Curl $=\mathrm{C}$ ) and average particle size $(\mathrm{P})$ of birch and softwood kraft pulps before and after 6 min of disintegration treatment

\begin{tabular}{|c|c|c|c|c|c|c|c|c|c|c|c|c|}
\hline & $\mathrm{Ba}$ & $\mathrm{Bb}$ & $\mathrm{Bc}$ & $\mathrm{Bd}$ & $\mathrm{Be}$ & $\mathrm{Bf}$ & $\mathrm{Sa}$ & $\mathrm{Sb}$ & $\mathrm{Sc}$ & $\mathrm{Sd}$ & $\mathrm{Se}$ & Sf \\
\hline $\mathrm{NaClO}$ & 0 & 1.25 & 2.5 & 3.75 & 5 & 6.25 & 0 & 1.25 & 2.5 & 3.75 & 5 & 6.25 \\
\hline $\mathrm{L}(\mathrm{mm})$ & 0.91 & 0.93 & 0.94 & 0.95 & 0.96 & 0.97 & 2.54 & 2.74 & 2.78 & 2.76 & 2.77 & 2.74 \\
\hline $\mathrm{W}(\mu \mathrm{m})$ & 17.4 & 16.9 & 16.8 & 16.8 & 16.7 & 16.9 & 27.5 & 26.9 & 26.2 & 25.6 & 26.1 & 28.1 \\
\hline $\mathrm{F}(\%)$ & 2.49 & 2.18 & 2.06 & 1.72 & 1.51 & 1.37 & 2.47 & 1.78 & 2.32 & 2.50 & 2.04 & 1.52 \\
\hline $\mathrm{C}(\%)$ & 16.7 & 12.3 & 11.1 & 10.7 & 9.2 & 10.5 & 24.6 & 21.0 & 18.5 & 16.0 & 15.4 & 17.0 \\
\hline $\mathrm{L}(\mathrm{mm})$ & - & 1.04 & 0.81 & 0.54 & 0.38 & 0.32 & - & 1.93 & 1.48 & 0.75 & 0.26 & 0.4 \\
\hline $\mathrm{F}(\%)$ & - & 3.3 & 3.8 & 15.8 & 40.4 & 36.3 & - & 5.5 & 15.1 & 19.2 & 44.7 & 75.0 \\
\hline $\mathrm{P}(\mu \mathrm{m})$ & - & 79 & 91 & 91 & 58 & 46 & - & 123 & 111 & 120 & 69 & 27 \\
\hline
\end{tabular}

Fig. 3 Particle size distributions of oxidized birch (left) and softwood (right) kraft pulp fibers after 6 min of disintegration treatment. Pulps were oxidized with various amounts of primary oxidant (1.25-6.25 mmol NaClO/g pulp)

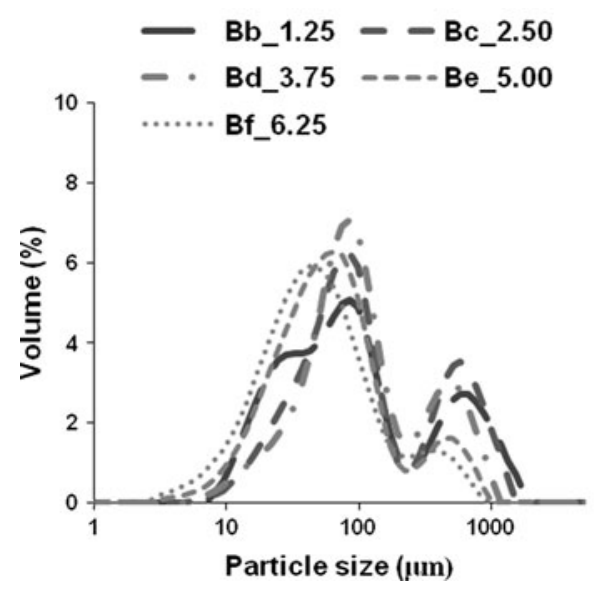

all conditions, but the peek with the largest particles decreased with increasing harshness of the oxidation. The softwood sample also started with a bi-modal shape, but the peek with the larger particles disappeared at the two harshest conditions. Thus, these results show that the oxidized softwood fibers are more easily disintegrated than birch fibers given the same treatment, and that the birch sample had fibers present even after the harshest oxidation.

Morphology of TEMPO-oxidized fibers and superabsorbent foams

Two SEM micrographs are shown in Fig. 4 as an example of softwood pulp fibers before oxidation treatment and after the harshest oxidation treatment. Considering the extent of chemical modification, more drastic changes could have been expected. However, the pulp fibers retained their fibrous morphology and no significant signs were seen of fiber damage or external fibrillation. The differences observed during microscopy analysis of the samples were that the surfaces of the oxidized fibers in many cases appeared to be smoother and that the oxidized fibers, in general, were straighter than the non-oxidized fibers. The SEM micrographs of the oxidized birch pulp fibers showed no other trends than what was observed in the softwood samples.

The morphology of the freeze-dried foams was also studied with SEM and a major difference between the samples treated with mild and harsh oxidation was found, cf. Fig. 5. The birch and softwood samples treated with mild oxidation had a relatively open fibrillar network with fibers present in the fibrillar matrix. The samples treated with the harshest oxidation treatment had narrower and more defined pores than the samples with a lower dosage of primary oxidant. This is important since narrower pores generate larger capillary forces than larger pores if all other factors are left unchanged. The pore structure 

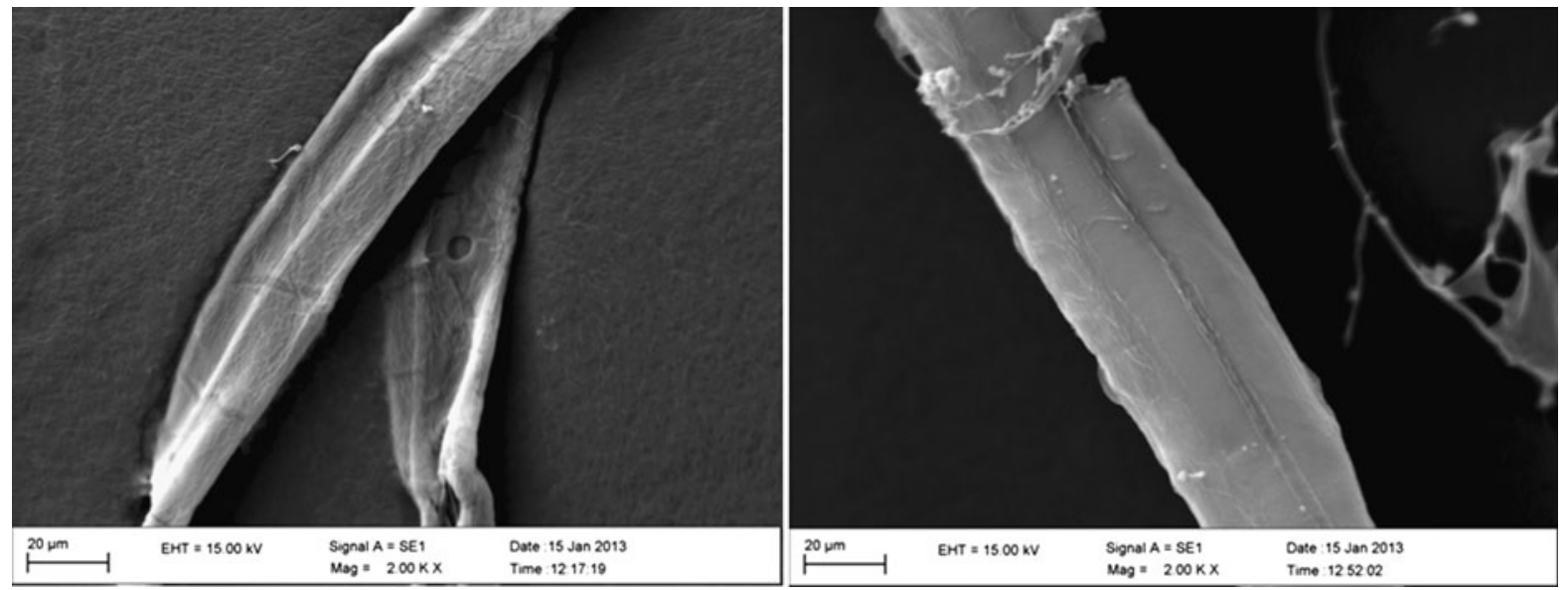

Fig. 4 Scanning electron micrographs at $\times 2000$ magnification of softwood kraft pulp fibers before $($ Sa $=$ left image $)$ and after the harshest TEMPO oxidation treatment $(\mathrm{Sf}=$ right image $)$

$\mathrm{b}=1.25 \mathrm{mmol} / \mathrm{g}$ pulp
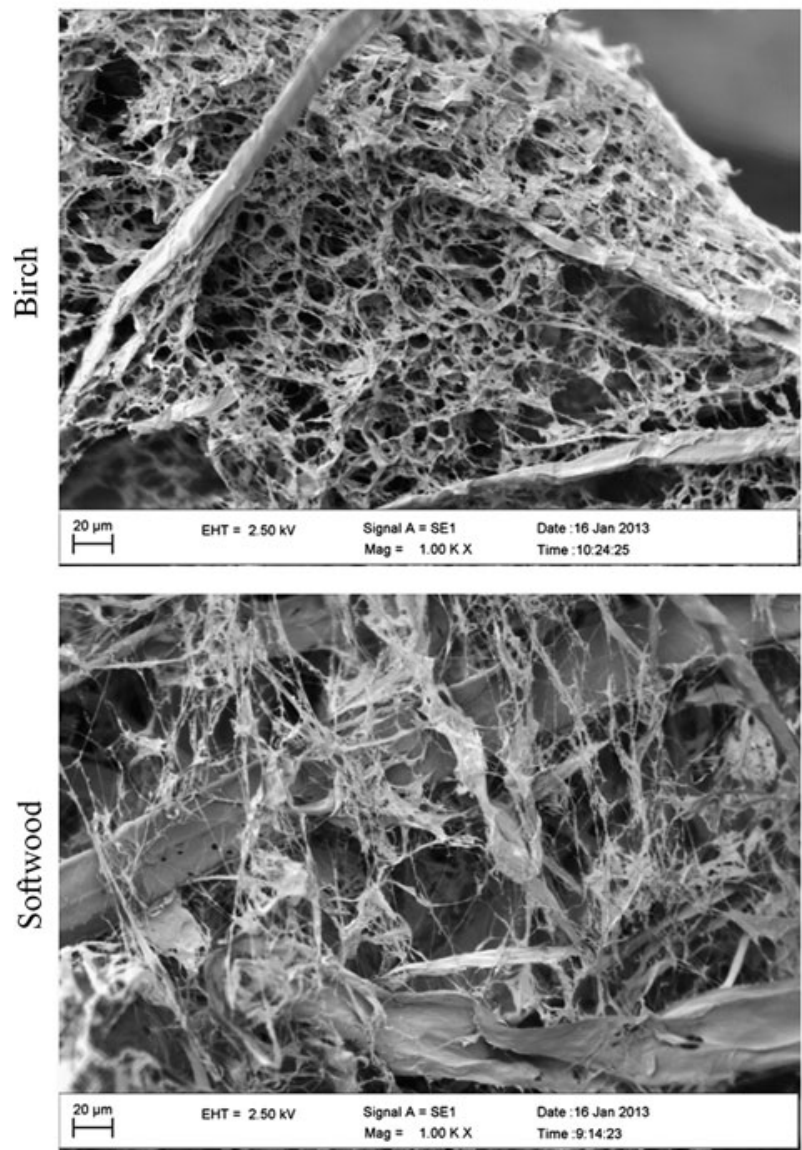

$\mathrm{f}=6.25 \mathrm{mmol} / \mathrm{g}$ pulp
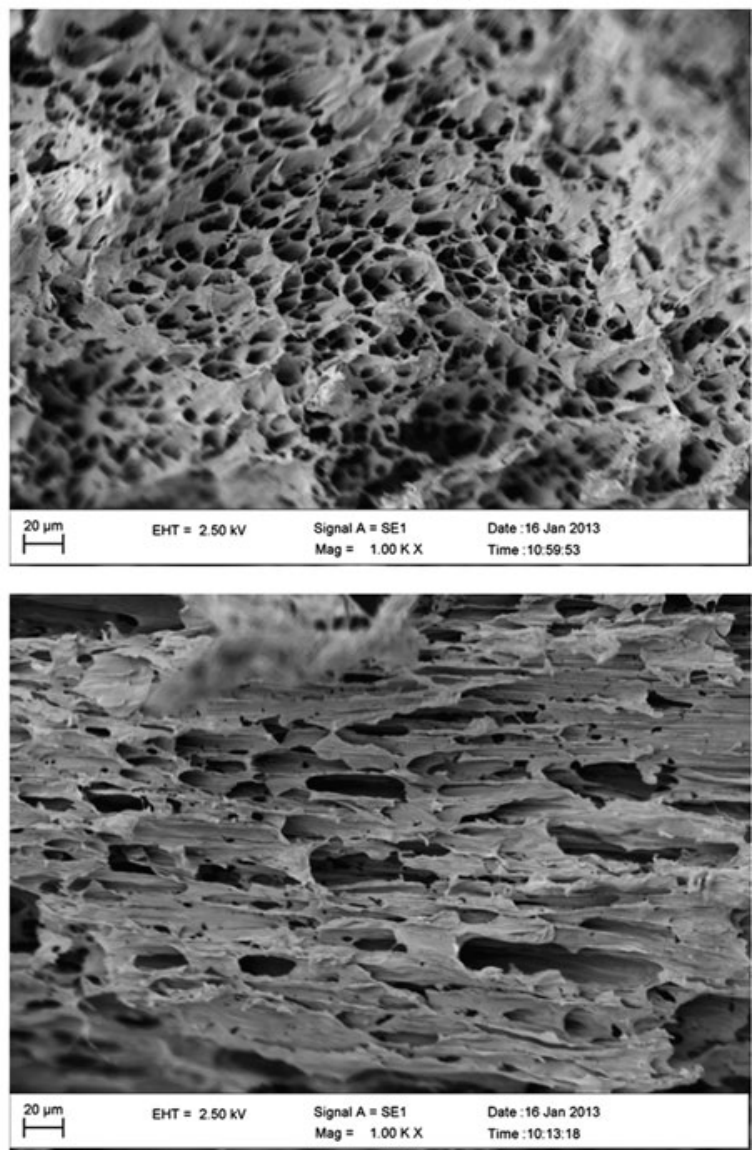

Fig. 5 Scanning electron micrographs at $\times 1000$ magnification of freeze-dried absorbent foams. Pulp type and dosage of primary oxidant are according to notations in the figure 
observed in the foams was formed during the freezing operation in liquid nitrogen, where the solid material was concentrated and finally pressed together between the growing ice crystals. It has previously been shown that the freezing conditions have a large influence on the pore morphology (cf. e.g. Deville (2008); Köhnke et al. (2012)). The rapid freezing by liquid nitrogen promotes formation of small ice crystals and most likely also formation of small sized pores in the foams.

\section{Absorbent properties of superabsorbent foams}

Absorption capacities were similar in birch and softwood foams, and the highest absorption capacities were obtained at moderate oxidations. Determinations of retention capacity showed that absorbent foams produced from birch pulp had on the average, $30 \%$ better ability to retain saline liquid than absorbent foams produced from softwood pulp, cf. Fig. 6. The difference in retention between the birch and softwood foams was the greatest after mild oxidations. The maximal retention capacity was obtained at the harshest oxidations but for softwood foams the increase in retention leveled out and was similar for moderate and harsh oxidations. The difference in retention capacity between birch and softwood samples is likely to be an effect of at least two different causes: one is smaller pore size in the material, since capillary forces are greater in smaller pores than in larger pores. One possible explanation is that the smaller pore size is related to the higher concentration of xylan in the birch pulp samples, because low molecular carbohydrates, mostly hemicelluloses, are expected to be found in the sheet-like structures that separate the pores from each other. The second difference between the birch and the softwood foams produced by harsh oxidation is the presence of fibers in the birch foams. These fibers are likely to contribute to absorption and retention capacity by reinforcing the foam and making it more resistant when subjected to external pressures (Brodin et al. 2012). Nevertheless, it must be noted that only a small amount of birch fibers remained after disintegration in relation to the fiber additions made in Brodin et al. (2012). On the other hand, the birch fibers may be oxidized on the surface to some extent and this may contribute to a more stable network due to the possibility of forming hemiacetal bonds between the fibers. The contribution to liquid absorption and retention by osmotic pressure is expected to be more or less similar for both pulp types, since the amount of carboxylate groups was similar in both pulp types given the same dosage of primary oxidant.

Influence of the extent of disintegration treatment

Figure 7 shows how the fiber length of oxidized pulp of birch and softwood decreased at different times of disintegration treatments and, consequently, how the content of fines increased as fibers were being disintegrated. It was found that the disintegration of softwood pulp fibers was more rapid than the disintegration of birch pulp fibers with respect to fiber length. Softwood fibers with an original length of $2.57 \mathrm{~mm}$ were broken down to an average fiber length of $0.15 \mathrm{~mm}$ at the longest treatment time. The corresponding fiber lengths for birch were $0.92-0.33 \mathrm{~mm}$. Furthermore, it must be noted that much of the material in the sample had a much smaller size than that, since fibrils were not detected in the fiber analysis. More fibers remained in the birch pulp samples, as shown by the decrease in fines content after 10-15 min of
Fig. 6 Absorption and retention capacity for freeze-dried foams plotted versus the dosage of primary oxidant. All samples were treated with 6 min of disintegration treatment prior to freeze drying
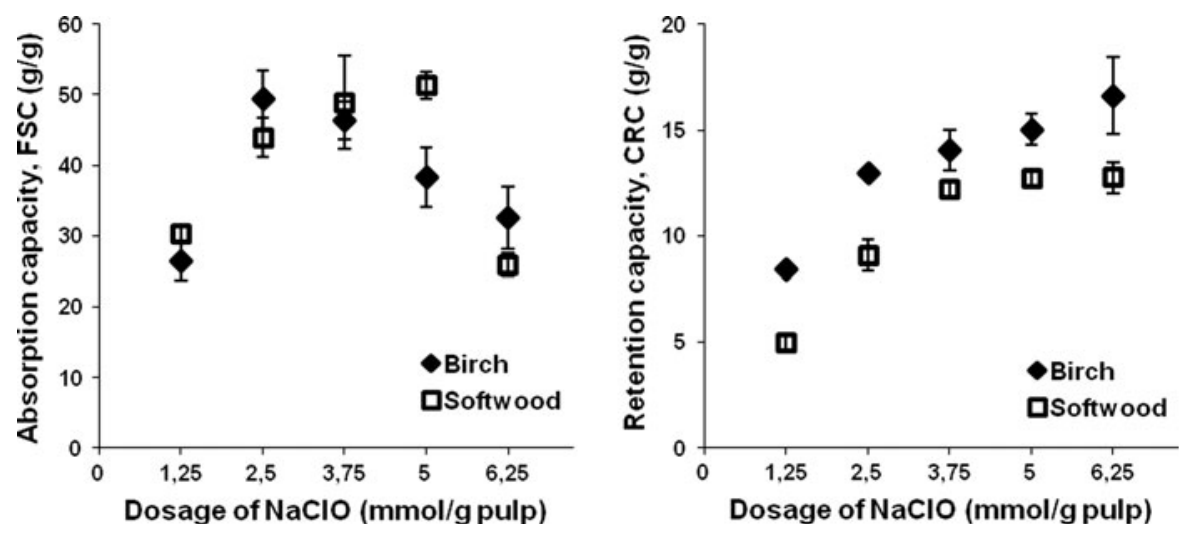
Fig. 7 Comparison of average fiber length and content of fines plotted versus disintegration time of TEMPO-oxidized birch and softwood kraft pulp fibers. Pulps were oxidized with $5 \mathrm{mmol} \mathrm{NaClO} / \mathrm{g}$ pulp. Average fiber length of oxidized softwood pulp prior to disintegration was $2.57 \mathrm{~mm}$ (data point not shown in figure)

Fig. 8 Particle size distributions of oxidized birch (left) and softwood (right) kraft pulp fibers after various amounts of disintegration treatment. Pulps were oxidized with $5 \mathrm{mmol} \mathrm{NaClO} / \mathrm{g}$ pulp
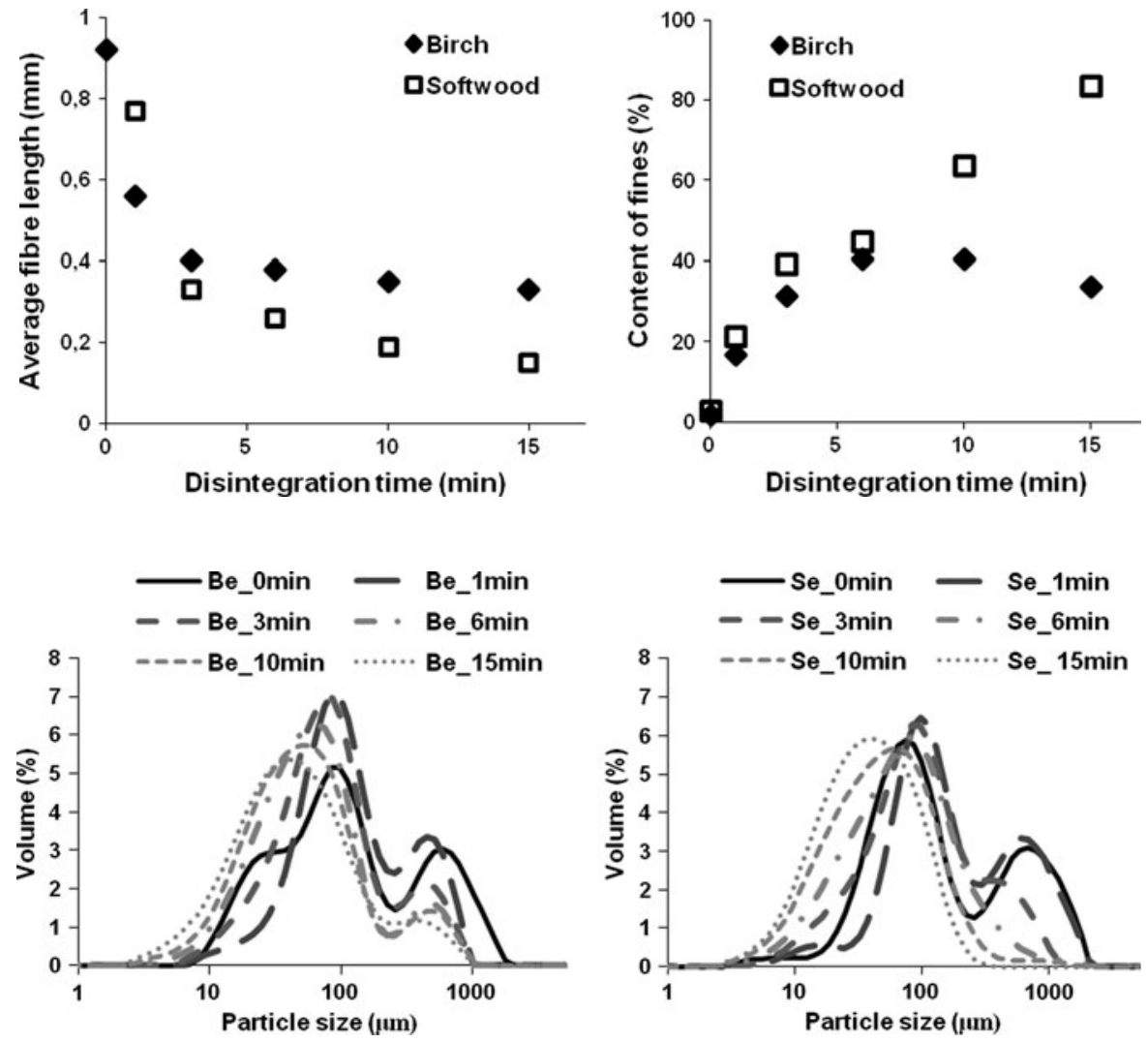

Fig. 9 Absorption and retention capacity for freeze-dried foams after various amounts of disintegration treatment. Pulps were oxidized with $5 \mathrm{mmol} \mathrm{NaClO} / \mathrm{g}$ pulp

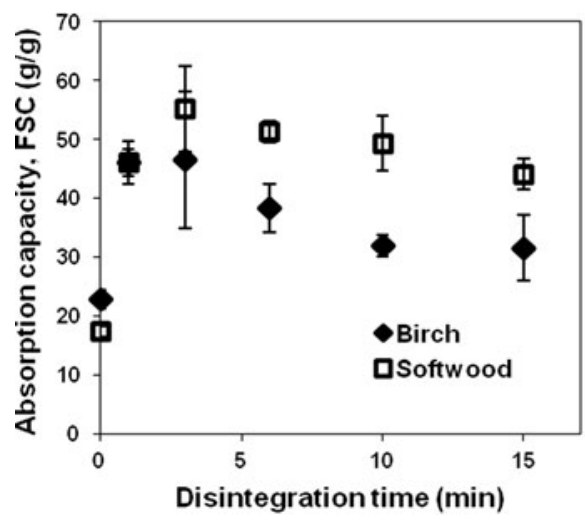

treatment. Thus, it appears that some fibers in the birch pulp were harder to break than other birch fibers. This may be related to the more diverse types of wood cells in birch wood than in softwood. In softwood 90-95\% of the wood cells are tracheids, while birch contains about $70 \%$ libriform cells, $25 \%$ vessel cells and in addition to this also some tracheid cells (Sjostrom 1993). Nevertheless, the difficulties in defibrillating hardwood fibers are in agreement with earlier studies (Stelte and Sanadi 2009; Syverud et al. 2011).
Figure 8 shows the particle size distributions that describe the gradual disintegration of the oxidized birch and softwood pulps. In these experiments some fibers remained in the birch pulp samples even at longer treatments (10-15 min), indicating that the birch pulp fibers were more difficult to disintegrate. In the softwood sample, most fibers were disintegrated after a treatment time of $6 \mathrm{~min}$.

Figure 9 shows that liquid retention and absorption increased rapidly given only a short treatment 
in the dispersing equipment. The maximal retention capacity was reached after about 6 min of disintegration for birch foams and thereafter it leveled out or possibly decreased somewhat, while the retention capacity for softwood samples was found to increase slightly if subjected to further disintegration treatment. The highest absorption capacities were obtained after about $3 \mathrm{~min}$ of treatment. Thus, there is an optimal length of disintegration treatment for reaching a maximum in either retention or absorption capacity, which depends both on the pulp source and extent of oxidation treatment.

\section{Conclusions}

- Superabsorbent foams prepared from birch kraft pulp had greater retention capacity than softwood kraft pulp foams at all oxidations. The produced foams had absorption capacities of 25-55 g/g and retention capacities of up to $16.6 \mathrm{~g} / \mathrm{g}$.

- Oxidized softwood kraft pulp fibers were easier to disintegrate, quantitatively, than birch pulp fibers where a small fraction of fibers remained even after the harshest oxidation or longer disintegration treatment.

- Fiber analysis and SEM analysis showed that both softwood and birch kraft pulp maintained its fibrous morphology during oxidation and no significant external defibrillation was observed with SEM analysis of the pulp fibers.

- The harshest oxidations of the pulps resulted in a yield loss of about $15 \%$, which to a major extent, could be attributed to the decrease in hemicelluloses content in the pulps.

Acknowledgments The authors would like to express gratitude to "Södra Skogsägarnas stiftelse för forskning, utveckling och utbildning', SCA Hygiene Products AB and VINNOVA for financial support in the project. Lena Fogelquist and Susanne Svensson are acknowledged for assistance in carbohydrate analysis and Tommy Friberg for performing measurements of intrinsic viscosity.

Open Access This article is distributed under the terms of the Creative Commons Attribution License which permits any use, distribution, and reproduction in any medium, provided the original author(s) and the source are credited.

\section{Appendix}

The relative carbohydrate composition was calculated from sugar analysis based on the following assumptions/corrections:

The amount of sugars analyzed was corrected for the acid hydrolysis yield. The anhydro sugars were calculated by removing a water molecule, i.e. by multiplying by 0.88 in the case of pentosans and by 0.90 in the case of hexosans. The ratio of mannan and glucan in glucomannan was assumed to be 3.5:1 in softwood pulp samples (Meier 1958) and 1.1:1 in birch pulp samples (Timell 1960). No analysis of 4-Omethylglucuronic and hexenuronic acids was made in this study, which implies that the xylan content was underestimated by at the most $0.5 \%$. Cellulose was calculated as the content of glucan after the removal of the glucan included in the glucomannan calculation.

The relative carbohydrate composition in softwood samples was calculated using the following formulas*:

Cellulose $=$ Glucose $-(1 / 3.5) \times$ Mannose.

Glucomannan $=$ Galactose $+(1+(1 / 3))$ $\times$ Mannose.

Xylan $=$ Xylose + Arabinose.

The relative carbohydrate composition in birch samples was calculated using the following formulas*:

Cellulose $=$ Glucose $-(1 / 1.1) \times$ Mannose.

Glucomannan $=(1+(1 / 1.1)) \times$ Mannose.

Xylan $=$ Xylose.

*Amount of anhydro sugars were divided by the hydrolysis yield before calculating the carbohydrate composition.

The following formulas were used to calculate effect on yield by the oxidation treatment:

Yield gain $(\%)=$ Amount of carboxylate groups introduced $[\mathrm{mol} / \mathrm{g}] \times$ change in molecular mass $[\mathrm{g} / \mathrm{mol}] \times 100$.

Where the change in molecular weight per carboxylate group was $1 \mathrm{Na}+1 \mathrm{O}-3 \mathrm{H}$.

Yield loss $(\%)=$ Gravimetrical yield

$$
-(100+\text { yield gain }) \text {. }
$$


Hemi loss $(\%)=$ Hemicelluloses in oxidized pulp

- Hemicelluloses in non

- oxidized pulp.

Where the values are based on the relative carbohydrate composition.

$$
\begin{aligned}
\text { Sugar acids }(\%)= & \text { Amount of carboxylate groups } \\
& {[\text { mol } / \mathrm{g} \text { pulp }] \times \text { molecular mass of } } \\
& \text { glucan with carboxylate group } \\
& \text { and a sodium counter }- \text { ion } \\
& {[\mathrm{g} / \mathrm{mol}] \times 100 . }
\end{aligned}
$$

Hydrolysis yield loss $(\%)=100$

$$
\text { - (hydrolysis yield/0.85). }
$$

where 0.85 represents the yield loss of a non-oxidized pulp. The non-oxidized birch pulp (Ba) was compensated with its hydrolysis yield of $78 \%$, thus having a hydrolysis yield loss of $0 \%$.

\section{References}

Allan D (1998) Other superabsorbent polymer forms and types. In: Buchholz F, Graham A (eds) Modern superabsorbent polymer technology. Wiley-VCH, New York, p 233

Bowman M, Dien B, O'Bryan P, Sarath G, Cotta M (2011) Selective chemical oxidation and depolymerization of switchgrass (Panicum virgatum L.) xylan with oligosaccharide product analysis by mass spectrometry. Rapid Commun Mass Spectrom 25:941-950

Bragd P, Besemer A, van Bekkum H (2000) Bromide-free TEMPO-mediated oxidation of primary alcohol groups in starch and methyl $\alpha$-D-glucopyranoside. Carbohydr Res 328:355-363

Brodin F, Theliander H (2012) Absorbent materials based on kraft pulp: preparation and material characterization. BioResources 7(2):1666-1683

Brodin F, Lund K, Brelid H, Theliander H (2012) Reinforced absorbent material-a cellulosic composite of TEMPO-oxidized MFC and CTMP fibres. Cellulose 19(4):1413-1423

Chatterjee P, Makoui K (1984) Freeze dried microfibrilar cellulose. US Pat 4:474-949

Davidson G (1948) Acidic properties of cotton cellulose and derived oxy-celluloses, part 2: absorption of methylene blue. J Text Inst 39:T65-T86

de Nooy A, Besemer A, van Bekkum H, van Dijk J, Smith J (1996) TEMPO-mediated oxidation of pullan and influence of ionic strength and linear charge density on the dimensions of the obtained polyelectrolyte chains. Macromolecules 29:6541-6547

DesMarais T, Stone K, Thompson H, Young G, LaVon G, Dyer C (1993) Absorbent foam materials for aqueous body fluids and absorbent articles containing such materials. US Pat 5:260-345

DesMarais T, Stone K, Thompson H, Young G, LaVon G, Dyer C (1994) Absorbent foam materials for aqueous body fluids and absorbent articles containing such materials. US Pat 5:015-331

Deville S (2008) Freeze-casting of porous ceramics: a review of current achievements and issues. Adv Eng Mater 10(3):155-169

Fujisawa S, Isogai T, Isogai A (2010) Temperature and $\mathrm{pH}$ stability of cellouronic acid. Cellulose 17(3):607-615

Griesbach H (1996) Starch foams for absorbent articles. US Pat 5:277-506

Harper B, Bashaw R, Atkins B (1972) Absorbent product containing a hydrocellodial composition. US Pat 3:103-669

Hubbe M, Rojas O, Lucia L, Sain M (2008) Cellulose nanocomposites: a review. BioResources 3(3):929-980

Isogai A, Kato Y (1998) Preparation of polyuronic acid from cellulose by TEMPO-mediated oxidation. Cellulose 5:153-164

Isogai T, Saito T, Isogai A (2010) TEMPO electromediated oxidation of some polysaccharides including regenerated cellulose fiber. Biomacromolecules 11:1593-1599

Jetten J, Van Den Dool R, Van Hartingsveldt W, Besemer A (2000) Process for selective oxidation of cellulose. WO Patent 050-463. Aug 31

Jones K, Lothian B, Martin A, Taylor G, Haq Z (1986) Porous polymers. US Pat 4:334-612

Kelly D, Kim D (1991) Highly absorbent polyurethane foam. US Pat 4:467-985

Köhnke T, Lin A, Elder T, Theliander H, Ragauskas A (2012) Nanoreinforced xylan-cellulose composite foams by freeze-casting. Green Chem 14:1864-1869

Makoui K, Chatterjee P (1987) Cross-linked pore containing microfibrillated cellulose prepared by freezing and solvent exchange. US Pat 4:118-689

Marchessault R, Ranby B (1959) Hydrolysis of cellulose in phosphoric acid solution-inductive effects. Svensk Papperstidning 62:230-240

Meier H (1958) Studies on hemicelluloses from pine (Pinus Sylvestris L.). Acta Chem Scand 12:1911-1918

Nagorski H (1994) Characterization of a new superabsorbent polymer generation. In: Buchholz F, Peppas N (eds) Superabsorbent technology: Science and technology. American chemical society, Washington, pp 101-103

Okita Y, Saito T, Isogai A (2010) Entire surface oxidation of various cellulose microfibrils by TEMPO-mediated oxidation. Biomacromolecules 11:1696-1700

Rodionova G, Saito T, Lenes M, Eriksen O, Gregersen O, Fukuzumi H, Isogai A (2012) Mechanical and oxygen barrier properties of films prepared from fibrillated dispersions of TEMPO-oxidized Norway spruce and Eucalyptus pulps. Cellulose 19(3):705-711

Rodionova G, Saito T, Lenes M, Eriksen $\varnothing$, Gregersen $\varnothing$, Kuramae R, Isogai A (2013) TEMPO-mediated oxidation of Norway spruce and Eucalyptus pulps: preparation and characterization of nanofibers and nanofiber dispersions. J Polym Environ 21(1):207-214

Saito T, Nishiyama Y, Putaux J-L, Vignon M, Isogai A (2006) Homogeneous suspensions of individualized microfibrils from TEMPO-catalyzed oxidation of native cellulose. Biomacromolecules 7:1687-1691

Saito T, Hirota M, Tamura N, Kimura S, Fukuzumi H, Heux L, Isogai A (2009) Individualization of nano-sized plant cellulose 
fibrils by direct surface carboxylation using TEMPO catalyst under neutral conditions. Biomacromolecules 10:1992-1996

Scallan M, Tigerstrom A (1992) Swelling and elasticity of the cell walls of pulp fibers. J Pulp Pap Sci 18(5):188-193

Seth R (2006) The importance of fibre straightness for pulp strength. Pulp Paper Can 107(1):34-42

Shibata I, Isogai A (2003) Depolymerization of cellouronic acid during TEMPO-mediated oxidation. Cellulose 10:151-158

Sierakowski M, Milas M, Desbrières J, Rinaudo M (2000) Specific modifications of galactomannans. Carbohydr Polym 42:51-57

Siro I, Plackett D (2010) Microfibrillated cellulose and new nanocomposite materials: a review. Cellulose 17:459-494

Sjostrom E (1993) Wood chemistry: Fundamentals and applications, 2nd edn. Academic press, San Diego

Staples TL, Chatterjee PK (2002) Synthetic Superabsorbents. In: Chatterjee PK, Gupta B (eds) Absorbent Technology. Elsevier Science B.V., Amsterdam, pp 283-322
Stelte W, Sanadi A (2009) Preparation and characterization of cellulose nanofibers from two commercial hardwood and softwood pulps. Ind Eng Chem Res 48:11211-11219

Syverud K, Chinga-Carrasco G, Toledo J, Toledo P (2011) A comparative study of eucalyptus and pinus radiata pulp fibres as raw materials for production of cellulose nanofibrils. Carbohydr Polym 84:1033-1038

Theander O, Westerlund E (1986) Studies on dietary fiber. 3. Improved procedures for analysis of dietary fiber. J Agric Food Chem 34:330-336

Timell T (1960) Isolation of hardwood glucomannans. Svensk papperstidning 63:472-476

Viikari L, Kruus K, Buchert J (1999) Method for modification of cellulose. WO Pat 9:117-923

Wigell A, Brelid H, Theliander H (2007) Degradation/dissolution of softwood hemicellulose during alkaline cooking at different temperatures and alkali concentrations. Nord Pulp Pap Res J 22(4):488-494 